\title{
Phenomenology Study of Stunting Nutrition for Babies in the Work Area of Pante Kuyun Health Center, Aceh Jaya District
}

\author{
Amiruddin Amiruddin*, Bustami Bustami, Anasril, Tri Mulyono Herlambang, Muhammad Husaini, Sri Gustini \\ Department of Nursing, Ministry of Health Polytechnic of Meulaboh, Aceh, Indonesia
}

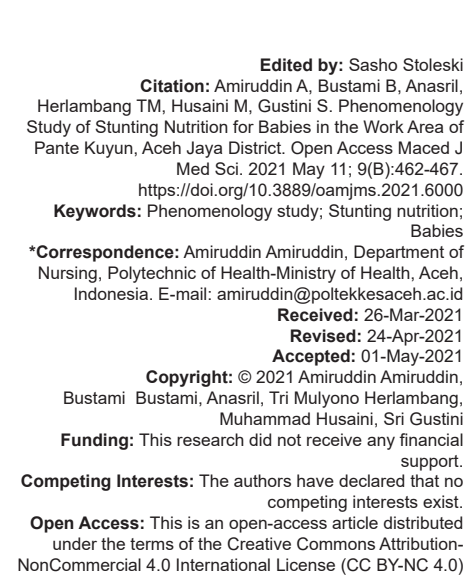

Introduction

The 2018 Basic Health Research results show that stunting prevalence is still high at $30.8 \%$ [1]. This number is still above the World Health Organization (WHO) stunting limit, which is $<20 \%$. This means that around 8.9 million Indonesian children experience sluggish growth, or 1 in 3 Indonesian children is stunted. Of the 34 provinces in Indonesia, 18 provinces have a prevalence of stunting above the national average. The province with the highest prevalence of stunting was East Nusa Tenggara (42.7\%) followed by West Sulawesi (41.6\%) and Aceh (37.1\%) [2].

\begin{abstract}
BACKGROUND: Stunting causes organs not to grow and develop optimally. One of the factors that indirectly

AIM: This is to find out the nutrition parenting patterns of children who are stunted in the working area of the Health Center Pante Kuyun, Aceh Jaya Regency.

METHODS: This study uses qualitative methods with a phenomenological approach. This research was conducted

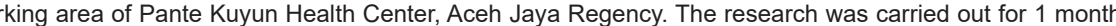
starting from August to September. The choice of research location was due to the high incidence of stunting in the area. The number of samples was determined 15 people consisting of 10 children under five who were stunted recording devices, video recording devices (camcorders), tape recorders, group discussion guidelines, and field notes. Data analysis techniques used in qualitative research include transcript analysis of interview results, data restrictions recommended by their parents and in-laws. The number of taboo foods to be consumed during pregnancy to generally comes from the food group of animal protein sources such as squid, shrimp, crab, shellfish, an is difficult to pass. It turns out that the customs, culture, and hereditary habits that continue to be carried out influence stunting in children under five. The pattern of nutrition parenting during the postpartum, postpartum period also causes turns out that the lack of intake during the postpartum period up to 40 days has an impact on the health of the postpartum, postpartum mother, especially only a little breast milk, dry skin, weakness, dizziness, and even sickness. Community exclusive; breastfeeding. Exclusive breastfeeding is not given to children due to the mother's lack of knowledge about exclusive breastfeeding benefits. The eating habit prioritizes elders' advice such as parents, in-laws, and religious leaders are still related to myths about health and nutrition in pregnant women and toddlers. The pattern of nutrition parenting performed by mothers for infants $>6$ months is not under the Indonesian Ministry of Health recommendations. In the Aceh Jaya district, mothers habitually give instant noodles as a substitute for the rice to consume toddlers. However, their mothers also have parenting styles, whereas if the working mothers provide food for toddlers, they are older siblings grandmothers, or nieces. Inadequate care, such as improper feeding from infancy to toddlerhood, causes toddlers to
\end{abstract}

CONCLUSION: Parenting affects toddlers who experience stunting in the working area of Pante Kuyun Community Health Center, Aceh Jaya Regency

Current problems in Indonesia include two things, namely overnutrition and burden of malnutrition. Excess nutrition includes overweight and obesity, while malnutrition includes wasting, underweight, and stunting. The direct factors causing stunting are nutrient intake and infectious diseases, and health status, while the indirect factors that cause stunting are environmental conditions, maternal care, and food availability. The consequences of child stunting are immediate and longterm and include increased morbidity and mortality, low child development and learning capacity, increased risk of infection and non-communicable diseases in adulthood, and decreased productivity and economic capacity [3]. Stunting in childhood has consequences 
that affect the health and development of human resources. In addition to low physical growth, stunting affects children's risk of infection and death, cognitive and motor development, learning capacity, and school performance. The Aceh Jaya Health Office stated that stunting cases in Aceh Jaya District were still very high, namely in 2019, it had reached 814 cases, so joint handling was needed to reduce this number. Data from the Health Office states that in 2016 were 996 cases of stunting in Aceh Jaya, 2017, as many as 1089 people, and in 2018 was 1085 people. This number has increased compared to 2016-2017, and there was a slight decrease in 2018 depkes [4].

According to UNICEF's framework, one of the factors that indirectly influence children's growth and development is the mother's care [5]. Parenting includes the family's ability to provide time, attention, and support in meeting the physical, mental, and social needs of children growing in the family. The pattern of caring for children is manifested in several ways: Breastfeeding and complementary foods, psychosocial stimulation, hygiene, and environmental sanitation practices, care for children in sickness in the form of health practices at home, and patterns of seeking health services. Habits in the family exist in feeding practices, psychosocial stimulation, hygiene practices, environmental sanitation, and utilization of health services. Mothers with less/low parenting styles have a greater chance of their children experiencing stunting than mothers with suitable parenting styles [6]. The mother's health care pattern also affects children's health status under five, which indirectly affects nutritional status [7]. Many maternal and child health problems are related to cultural and societal problems, including malnutrition and stunting [8], [9]. The culture and local knowledge regarding Nutrition Parenting that developed in many communities is thought to have contributed to stunting. Therefore, it is necessary to carry out Phenomenology research to analyze Nutritional Parenting Patterns of Toddlers Who Have Stunting in the Work Area of Pante Kuyun Community Health Center, Aceh Jaya Regency.

\section{Methods}

The method used is a qualitative method with a phenomenological approach. Phenomenological research tries to reveal the Exploration of a person's experience. The meaning experienced depends on how someone relates to something [10]. Phenomenology also means letting something come to manifest itself as it is. This research was conducted in the working area of Pante Kuyun Health Center, Aceh Jaya Regency. The research was carried out for 1 month, starting from August 10, 2020, to September 10, 2020 . The choice of research location was due to the high incidence of stunting in the area. The number of samples was determined as many as 15 people: 10 mothers with children under five, the head of the Health Center 1 person, the Aceh Jaya health office (2 people), and two community leaders. The informants are residents of Pante Kuyun, Aceh Jaya Regency and can communicate well to answer all the researchers' questions. The data collection technique involves standard procedure methods, such as in-depth interviews, focus group interviews, and observations. Observations were made in the research village, the socioeconomic conditions of postpartum mothers using the observation module. This study uses recording devices, video recording devices (camcorders), tape recorders, group discussion guidelines, and field notes. The software used in simplifying editing is the $N$-Vivo application. Data analysis techniques used in qualitative research include transcript analysis of interview results, data reduction, analysis, data interpretation, and triangulation.

\section{Results and Discussion}

This condition is measured by a length or height that is more than minus two standard deviations from the WHO median growth standard for children. Toddler stunting is a chronic nutritional problem caused by socioeconomic conditions, maternal nutrition during pregnancy, illness in infants, and lack of intake in infants. Stunting toddlers in the future will have difficulty achieving optimal physical and cognitive development [7]. Toddler stunting includes chronic nutritional problems caused by many factors such as socioeconomic conditions, maternal nutrition during pregnancy, infant illness, and lack of intake in infants. Stunting toddlers in the future have difficulty achieving optimal physical and cognitive development [7]. Many complex interplaying factors influence nutritional problems. Inadequate parenting styles applied by mothers/caregivers to toddlers can be among the causes of malnutrition in children under five at the household level [11]. Mother's behavior in caring for their toddlers is closely related to the incidence of stunting in toddlers. Mothers with good parenting tend to have children with good nutritional status, and vice versa, mothers with less nutritional care, tend to have low nutritional status [12]. Critical aspects of parenting consist of care and protection for mothers, breastfeeding and complementary foods, food preparation, environmental hygiene and sanitation practices, and health practices at home [13]. Based on the results of in-depth interviews and FGDs with all informants and supported by information from supporting informants, namely community leaders, nutrition parenting for stunted children is described in four sub-themes (1) nutrition parenting during pregnancy, (2) nutrition parenting during postpartum 
and infants aged 0-6 months, (3) nutrition patterns of infants $>6$ months -1 years, and (4) nutrition parenting for children aged $>1$ year.

\section{Nutrition parenting for pregnant women}

From the results of in-depth interviews with informants, it was found that one of the causes of stunting for toddlers is nutrition during pregnancy. During pregnancy, most mothers follow the restrictions recommended by their parents and in-laws. The number of dietary restrictions for consumption during pregnancy to breastfeeding generally comes from animal protein sources such as squid, shrimp, crab, shellfish, and so on because it is believed to cause the fetus to become sticky so that it complicates the delivery process and breast milk is difficult to pass. The types of avoided foods are suitable for consumption because they affect the growth of children who have started since they were still in the womb. The informants admitted that during pregnancy, they also lacked appetite and often had nausea and vomiting. The problem during pregnancy that often arises is the lack of appetite during pregnancy so that the consumption (portion) of food tends to be less than before pregnancy to experience food consumption problems during pregnancy. Infants who are malnourished since in the womb affect the fetus's organs and growth and tend to have low birth weight (LBW) [14]. Toddlers with LBW are more at risk of becoming stunted because LBW children have a higher susceptibility to infectious diseases, such as diarrhea and lower respiratory tract infections, and an increased risk of complications including sleep apnea, jaundice, anemia, chronic lung disorders, fatigue, and loss of appetite compared to children with average birth weight resulting in suboptimal physical growth [15]. Attention to mothers, such as increasing food intake during pregnancy about the nutritional status and health of pregnant women, is an important thing that significantly influences fetal growth and outcome of pregnancy. Research in Eastern Guatemala has shown that malnutrition during pregnancy contributes to low fetal growth [8].

The health of pregnant women can be realized by having a healthy lifestyle during pregnancy, namely taking good care of the pregnancy through adequate nutritional intake, taking iron tablets, doing pregnancy exercises, maintaining birth canals, avoiding smoking and taking the medication without a prescription, and making at least four visits. Times to get information from health workers about the treatment must be done [9]. Furthermore, several studies suggest that mothers who work 30 h/week cannot regulate the child's diet, which results in children experiencing nutritional status disorders, either being malnourished or inadequate, or even becoming overnourished and obese [16]. Several studies have also explained the relationship between parenting styles and nutritional status. However, parenting is mostly only in feeding practices [17]. This is also supported by research that reveals that LBW is the dominant factor affecting stunting incidence [18]. Parenting a child's diet in early life will determine children's health and development in the future [18]. Parenting is a practice applied by mothers to children covering situations and eating ways to provide a pleasant atmosphere for children at mealtime [19]. The latest quasi-experimental research in the form of communitybased health education carried out through routine health services and digital monitoring of malnutrition for children aged 6 months-1 year can increase the growth of children in vulnerable groups in northern India [20]. Knowledge, attitudes, and practices (KAP/knowledge, attitude, and practice) related to maternal nutrition are essential aspects in improving children's health. Knowledge related to maternal nutrition was assessed based on five primary nutritional and health information, namely: (1) The mother's knowledge of the importance of colostrum; (2) knowledge about breastfeeding; (3) knowledge of diarrhea prevention and treatment; (4) knowledge about child immunization; and (5) knowledge of family planning [21]

\section{Childhood nutrition and infant age 0-6 months}

During the puerperium, some cultures can sometimes not good for the mother's health and the health of the fetus. One culture is that restrictions on certain foods can make the breast milk content decrease, the mother's healing is delayed, and sometimes even an infection can occur. In-depth interviews and FGD with informants found that the same behavior was carried out by all the primary informants, namely the maddening culture. All postpartum mothers cannot avoid this maddening culture in Aceh Jaya. According to the informant's statement, out for 40 days after giving birth, during which time they not allowed to drink anything other than plain water, the amount of drinking was limited, likewise with eating. It is not allowed to eat foods other than white rice during the puerperium, and the fish are only anchovies.

It turns out that the lack of intake during the postpartum period up to 40 days has an impact on the health of the postpartum mother, especially only a little breast milk, dry skin, weakness, dizziness, and even sickness. Feeding and drinking other than breast milk for infants aged 0-6 months can cause the baby to experience digestive disorders, including diarrhea. Diarrhea is an infectious disease that is susceptible to babies; if this is not handled correctly, it can cause malnutrition. Babies who are deficient in nutrients for a long time have the potential to become stunted. The dietary parenting applied by mothers will affect the growth and development of toddlers because malnutrition during toddlerhood will be irreversible so that at this time, toddlers need quality food intake [22]. 
Research conducted in Tanzania on 37,409 toddlers showed that mothers who did not provide exclusive breastfeeding regularly were 3.46 times more likely and not exclusively breastfed were 4.29 times more likely to have stunted babies [23]. A recent study conducted in rural areas in Bangladesh shows that children who are stunted will experience a delay in puberty than children of the same age who are not stunted [24]. The nutritional adequacy of children is not only influenced by the intake of food but also the intake of breast milk given by the mother to the poor. Breast milk has sufficient nutrients for the needs of children. Breastfeeding given can prevent malnutrition in children, so the risk of stunting will be reduced.

\section{Baby nutrition parenting >6 months-1 year}

The results of in-depth interviews obtained information that children should not eat much fish because it could have worms. As a complementary food, the informants usually gave only softened rice and bananas. Fish and vegetables are not given until the child's age is over 1 year. Mothers have the habit of giving water with green coconut and honey water when the baby is born. Apart from babies aged 0 months to 6 months of age, they also receive other additional food in biscuits, eggs, meat, etc. This situation causes the mother not to provide early initiation of breastfeeding and exclusive breastfeeding to the baby. Most of the food consumption for toddlers is not following the dietary rules for toddlers according to age, and for example, when a toddler is not yet 1 year old, packaged snacks are already given to them from a shop. Lack of exclusive breastfeeding consumed by baduta made baduta deficient in nutrients that were not found in formula milk. Exclusive breastfeeding is not given to children due to the mother's lack of knowledge about exclusive breastfeeding benefits. The pattern of nutrition parenting performed by mothers for infants $>6$ months is not following the Indonesian Ministry of Health's recommendations. Some mothers in the study locations did not exclusively breastfeed their children because their breasts did not produce milk. The frequency of children's eating is also not given enough attention so that the eating schedule is irregular. The results of in-depth interviews with informants obtained information that their children were fed when they cried. Some set schedules, but their children do not want to eat or eat only a little. The reality in the research location is also known that the mother's age is determined, affecting parenting styles. Most of the research subjects were young mothers who married early, so it is assumed that they still have insufficient knowledge. Parenting by providing psychosocial stimuli to children will improve motor, cognitive, social, emotional, and character development [25]. In addition to the pattern of caring for children's food, there is also a need for health care that must be done frequently to form a habit to form related patterns in parenting that keep children healthy.
The pattern of parenting or the mother's habits in caring for her baby, divided into dietary care and health care, can affect nutritional status. Toddlers who receive exclusive breastfeeding have a 9.3 times lower risk of stunting than toddlers who do not receive exclusive breastfeeding [26]. Colostrum, exclusive breastfeeding, meal frequency, daily meal arrangement, daily side dishes, Vitamin A, and immunization were not significant in this study.

\section{Nutrition parenting for children aged $>1$}

year

Nutritional status is influenced by the consumption of food and the use of nutrients in the body [1]. The results of in-depth interviews with informants obtained information that children rarely eat fish because they are afraid of worms. Besides, an irregular meal schedule, not a balanced diet. Nutritional status is the state of the body as a result of food consumption and nutrient use. Most parents work, children are more often cared for by their grandmothers so that their diet follows the wishes of their grandmother based on family hereditary habits such as when babies are fed with bananas that are scraped and softened together. The eating habit prioritizes elders' advice such as parents, in-laws, and religious leaders are still related to myths about health and nutrition in pregnant women and toddlers. However, their mothers also have parenting styles, whereas if the working mothers provide food for toddlers, they are older siblings, grandmothers, or nieces. Inadequate care, such as improper feeding from infancy to toddlerhood, causes toddlers to suffer from illness more often due to disruption of digestion because the baby's intestines are still vulnerable. In the Aceh Jaya district, mothers habitually give instant noodles as a substitute for the rice to consume toddlers. This habit is because toddlers have difficulty eating, so mothers prefer to provide instant noodles, which toddlers prefer. Most mothers of toddlers provide food to their toddlers, so they are full and not fussy. The provision of such food is prioritized according to the child's wishes without paying attention to the nutritional value of a balanced diet so that the food consumed only contains carbohydrate sources

One of the causes of stunting is mothers' common knowledge while mothers are the primary caregivers for children. The limited knowledge of mothers about food choices, feeding, and healthcareseeking practices contributed significantly to their consequences under-nutrition in children under five in most developing countries [21]. Increasing maternal knowledge is one of the keys to reducing the incidence of stunting. Mothers in Indonesia are generally the primary caregivers for children, and that maternal education is related to protective behaviors, including increased visits to the health centers for child immunizations, health education, and vitamin 
A supports child growth and development [27]. In various studies, it is known that boys are more likely to be stunted than girls, and similar findings have been found in previous literature [28], [29]. This is postulated due to the increased susceptibility of boys to infections and other diseases that can interfere with the child's growth [30]. The results of recent studies conducted in rural areas in Bangladesh show that children who are stunted will experience delayed puberty compared to children of the same age who are not stunted [24]. The results of a recent study show that the incidence of stunting is associated with lower cognitive development in children at 5 years of age.

\section{Conclusion}

The results showed that there was an effect of parenting for toddlers who were stunted in the working area of Pante Kuyun Community Health Center, Aceh Jaya Regency. One of the causes of stunted toddlers in Aceh Jaya is healthy parenting during pregnancy. The cause of toddlers who experience stunting is healthy parenting during pregnancy. During pregnancy, most mothers follow the restrictions recommended by their parents and in-laws. The number of dietary restrictions for consumption during pregnancy to breastfeeding generally comes from animal protein sources such as squid, shrimp, crab, shellfish, and so on because it is believed to cause the fetus to become sticky so that it complicates the delivery process and breast milk is difficult to pass. Children rarely eat fish for fear of worms. Irregular eating schedule, the food menu is not regulated in a balanced manner. Nutritional status is the state of the body as a result of food consumption and nutrient use. It turns out that the customs, culture, and hereditary habits that continue to be carried out influence stunting in children under five. However, changing a belief and belief is not an easy matter; it needs continuous efforts to convince the public that not all cultures and habits that are carried out are good and have negative impacts on children's health.

\section{References}

1. Kementerian Kesehatan RI. Laporan Nasional Riskedas. Jakarta: Sekretariat Badan Litbang Kemenkes RI; 2018.

2. Ditjen Kesehatan Masyarakat. Buku Saku Pemantauan Status Gizi. Jakarta: Kemenkes RI; 2017.

3. Stewart CP, lannotti L, Dewey KG, Michaelsen KF, Onyango AW. Contextualising complementary feeding in a broader framework for stunting prevention. Matern Child Nutr. 2013;9(2):27-45. https://doi.org/10.1111/mcn.12088

PMid:24074316
4. Aceh Jaya Health Office; 2019.

5. United Nations Children's Fund (UNICEF), World Health Organization, International Bank for Reconstruction and Development. The World Bank. Levels and Trends in Child Malnutrition: Key Findings of the 2019 Edition of the Joint Child Malnutrition Estimates. Geneva: World Health Organization; 2019. https://doi.org/10.18356/1a56f529-en

6. Picauly I, Toy SM. Analysis of determinants and effects of stunting on the learning achievement of school children in Kupang and Sumba East, NTT. J Food Nutrition. 2013;8(1):5562. https://doi.org/10.25182/jgp.2013.8.1.55-62

7. Adriani M, Kartika V. Parenting patterns of eating in toddlers with status malnutrition in East Java, Central Java and Central Kalimantan, 2011. Health System Research. 2013;16(2):185-93. https://doi.org/10.31219/osf.io/dqwxz

8. Neufeld LM, Haas JD, Grajeda R. Changes in maternal weight from the first to second trimester of pregnancy are associated with fetal growth and infant length at birth. Am J Clin Nutr. 2004;79(4):646-52. https://doi.org/10.1093/ajcn/79.4.646 PMid:15051610

9. Istiany AR. Gizi Terapan, Ban-Dung: PT, Remaja Rosdakarya 2013.

10. Sugiyono. Metode Penelitian Kuantitaif, Kualitatif, dan R\&D, Bandung Alfabeta; 2011

11. Richard SA, Black RE, Gilman RH, Guerrant RL, Kang G, Lanata CF, et al. Wasting is associated with stunting in early childhood. J Nutr. 2012;142(7):1291-6. https://doi.org/10.3945/ jn.111.154922

PMid:22623393

12. Ni'mah C, Muniroh L. Relationship level of education, level knowledge and parenting patterns of mothers with wasting and stunting in children from poor families. Med Gizi Indonesia. 2016;10(1):84-90. https://doi.org/10.20473/amnt. v4i1.2020.49-57

13. Rahmad AH, Miko A. Study on stunting in toddlers based on parenting patterns and family income in the City Banda Aceh. Indonesian Public Health. 2016;8(2):63-79. https:// doi.org/10.33143/jhtm.v3i1.262. 2016;8(2):63-79. https://doi. org/10.33143/jhtm.v3i1.262

14. Checkley W, Bukley G, Gilman RH, Assis AM, Guerrant RL, Morris SS, et al. Multi-country analysis of the effects of diarrhoea on childhood stunting. Int J Epidemiol. 2008;37(4):816-30. https://doi.org/10.1093/ije/dyn099 PMid: 18567626

15. Rahman MM. Is unwanted birth associated with child malnutrition in Bangladesh? Int Perspect Sex Reprod Health 2015;41(2):80-8 PMid:26308260

16. Fertig A, Glomm G, Tchernis R. The connection between maternal employment and childhood obesity: Inspecting the mechanism. Rev Econ Househ. 2009;7(1):227-55. https://doi. org/10.1007/s11150-009-9052-y

17. Faiza $R$, Elnovriza $D$, Syafianti. Risk factors for malnutrition in children under five (12-59 months) in the working area of the puskesmas Andalas, Padang Timur District, Padang City in 2007. Family Nutrition Med. 2007;31(1):80-8. https://doi. org/10.25077/jka.v7.i2.p275-284.2018

18. Nadiyah N, Briawan D, Martianto D. Risk factors for stunting in children children aged 0-23 months in the Provinces of Bali, West Java, and Nusa East Southeast. J Food Nutrition. 2014;9(2):125-32. https://doi.org/10.33086/mtphj.v3i1.649

19. Ricci JA, Becker S. Risk factors for wasting and stunting among children in Metro Cebu, Philippines. Am J Clin Nutr. 2014;63(6):966-75. https://doi.org/10.1093/ajcn/63.6.966 PMid:8644694 
20. Sharma N, Gupta M, Aggarwal AK, Gorle M. Effectiveness of a culturally appropriate nutrition educational intervention delivered through health services to improve growth and complementary feeding of infants: A quasi-experimental study from Chandigarh, India. PLoS One. 2020;15(3):e0229755. https://doi.org/10.1371/ journal.pone.0229755

PMid:32182241

21. Fadare $O$, Amare M, Mavrotas G, Akerele D, Ogunniyi A. Mother's nutrition-related knowledge and child nutrition outcomes: Empirical evidence from Nigeria. PLoS One. 2019;14(2):e0212775. https://doi.org/10.1371/journal. pone.0212775

PMid:30817794

22. Martianto D, Ariani M. Analisis Perubahan Konsumsi dan Pola Konsumsi Pangan Masyarakat Dalam Dekade Terakhir. Jakarta: Prosiding WNPG VIII; 2004. p. 17-9.

23. Sunguya BF, Zhu S, Mpembeni R, Huang J. Trends in prevalence and determinants of stunting in Tanzania: An analysis of Tanzania demographic health surveys (1991-2016) Nutr J. 2019;18:85. https://doi.org/10.1186/s12937-019-0505-8

24. Svefors P, Pervin J, Khan Al, Rahman A, Ekström EC, El Arifeen $\mathrm{S}$, et al. Stunting, recovery from stunting and puberty development in the MINIMat cohort, Bangladesh. Acta Paediatr. 2020;109(1):122-33. https://doi.org/10.1111/apa.14929

PMid:31283046
25. Hastuti D, Fiernanti DY, Guhardja S. Environmental quality child care and social emotional development toddlers in food insecure areas. J Consumer Family Science. 2011;4(1):57-65. https://doi.org/10.24156/jikk.2011.4.1.57

26. Ogunba BO. Maternal behavioral feeding practices and underfive nutrition: Implication for child development and care. J Appl Sci Res. 2006;2(12):1132-6.

27. Hall C, Bennett C, Crookston B, Deardenc K, Hasan M, Linehan $\mathrm{M}$, et al. Maternal knowledge of stunting in rural Indonesia. Int J Child Health Nutr. 2018;7:139-45. https://doi. org/10.6000/1929-4247.2018.07.04.2

28. Cruz LM, Azpeitia GG, Súarez DR, Rodríguez AS, Ferrer JF, Serra-Majem L. Factors associated with stunting among children aged 0 to 59 months from the central region of mozambique. Nutrients. 2017;9(5):491. https://doi.org/10.3390/nu9050491 PMid:28498315

29. Damayanti RA, Muniroh L, Farapti F. Level difference nutritional adequacy and history of exclusive breastfeeding stunting and non-stunted toddlers. Med Gizi Indonesia. 2016;11(1):61-9. https://doi.org/10.20473/mgi.v11i1.61-69

30. Elsmén E, Pupp IH, Hellström-Westas L. Preterm male infants need more initial respiratory and circulatory support than female infants. Acta Paediatr. 2004;93(4):529-33. https://doi. org/10.1080/08035250410024998

PMid:15188982 